\title{
The Use of Standardized Patients in Athletic Training Education
}

\author{
Stacy E. Walker, PhD, ATC, Thomas G. Weidner, PhD, ATC, LAT, FNATA
}

Ball State University, Muncie, IN

Context: Standardized patients are widely used in health care programs to both teach and evaluate the communication and clinical skills of students. Although athletic training education programs (ATEPs) commonly use simulations, little information exists related to the use and implementation of standardized patients (SPs).

Objective: To provide strategies to use SPs with athletic training students and limited resources.

Background: Standardized patient encounters differ from simulations. Simulations require students to perform clinical skills on a mock patient or athlete who has no training to consistently portray a particular injury or illness. SP encounters are consistent, carefully crafted portrayals of injuries or illnesses by trained individuals.

Synthesis: A feasible way to use SPs in an ATEP is the time-in-time-out method which allows students to not only examine a SP, but also interact with and obtain immediate feedback from their instructor. Research with athletic training students has revealed that SP encounters are both realistic and worthwhile. Many resources exist to initiate the use of standardized patients in ATEPs, including various research publications, and online resources such as MedEd Portal and the Association of Standardized Patient Educators.

Results: The use of SPs enhances learning opportunities for students and provides a format for real-time evaluation for instructors.

Recommendation(s): Educators should consider using athletic training students and/or theater students to serve as SPs. Also, a local hospital or other SP programs at a local university may offer the use of their facilities or resources to initiate the use of SPs in your ATEP.

Conclusion(s): Many resources are needed to implement the use of standardized patients into an ATEP, but the experience can be well worth the expense to provide a realistic and worthwhile learning experience for students.

Key Words: Patient simulations, clinical proficiencies, proficiency evaluation

Dr. Walker is an Assistant Professor in the professional athletic training program at Ball State University. Please address all correspondance to Stacy E. Walker, PhD, ATC, School of Physical Education, Sport and Exercise Science, Muncie, IN 47306. sewalker@sbu.edu.

\section{Full Citation:}

Walker SE, Weidner TG. The use of standardized patients in athletic training education. Athl Train Educ J. 2010;5(2):87- 


\title{
The Use of Standardized Patients in Athletic Training Education
}

\author{
Stacy E. Walker, PhD, ATC and Thomas G. Weidner, PhD, ATC, LAT, FNATA
}

$\mathrm{I}$ ndividuals carefully trained to portray an injury or illnesses are referred to as standardized patients (SP). The SP undergoes anywhere from 4-10 hours of training to learn how to: 1) portray the SP case; 2) use a check sheet to evaluate student performance; and 3) provide general and specific performance feedback to the student. Standardized patients have been used in medical schools to teach and evaluate students since $1964,{ }^{1}$ and are now being used in nursing ${ }^{2,3}$ and physical therapy education. ${ }^{4,5}$ However, there has been little to no reported use of SPs in athletic training education. Currently, a majority of athletic training students' clinical proficiencies are evaluated via simulations. ${ }^{6,7}$ Simulations, however, require athletic training students to perform clinical skills on a mock patient or athlete who has no training to portray a particular injury or illness in a consistent fashion. ${ }^{6,7}$

SP encounters are very different from simulations, in that the SP case is carefully created with a template prior to the encounter itself. Creating cases and checklists, recruiting and training SPs, locating space, and conducting SP encounters can be very demanding on faculty time. In medical schools often there are individuals, such as Clinical Education Directors, SP trainers, and SP educators, hired to perform these tasks. In addition, most medical schools and some nursing programs have SP Centers comprised of 5-20 fully-equipped examination rooms which oftentimes all contain video recorders linked into a central viewing facility. It is unlikely such facilities will be available to ATEPs, unless they are at an institution with a medical school. However, even with time and resource barriers, our experience at Ball State University (BSU) reveals that ATEPs can still utilize SPs to help teach and evaluate athletic training students. The purpose of this commentary is to provide ways to use SPs with athletic training students and limited resources.

\section{Ways to Use SPs}

One way of utilizing SPs with limited resources is to use them for teaching purposes. For example, the time-in - time-out method, could be used to assist athletic training students in practicing both their clinical and communication skills while being provided immediate feedback. ${ }^{8}$ For the time-in - time-out method, multiple students are evaluated by one instructor and/or clinician, which can also save instructor and clinician time. Students in groups of 3-6 evaluate an SP with the instructor and clinician present. If the students become overwhelmed and are not sure how to continue, and/or the instructor/clinician wants to intervene, then a timeout is called. During this time-out, the SP goes into suspended animation and the students can discuss with their instructor/ clinician their thoughts about the case, possible next steps, or any other variety of things which would not normally be discussed in front of a patient. When time-in is called, the students then continue to interact with the SP. When students learn new clinical skills, such as injury evaluation or modality application, the timein - time-out method can allow students to interact with a SP and practice their skills prior to performing them on a patient. To minimize the need for multiple SPs, this method could be used during lab time to allow students to practice their clinical skills (eg, history taking, physical examination, and/or communication). Following the encounter, the instructors, SP, and students can discuss the tone, pacing, timing, phrasing of the history questions, as well as body language and eye contact with the patient. $A$ variety of different experiences can be practiced utilizing the timein - time-out method.

We have learned that not only can SP encounters provide students with realistic clinical scenarios (reference related SP article in this issue of ATEJ), but that students also receive valuable and immediate feedback from instructors, peers, and the SP. SPS also can provide realistic skill and communication practice for stressful situations such as spine boarding, facemask removal, notification of athletes and parents regarding a career-ending injury, and conflict with a parent and/or coach. In particular, students could use SPs to more realistically practice clinical skills that are often simply simulated or role played during their clinical education (eg clinical proficiencies from the Nutritional Aspects of Injury and IIIness, and Psychosocial Intervention and Referral educational content areas). ${ }^{7}$ For example, it is unlikely that an athletic training student would obtain significant experiences in counseling and referring a patient for drug abuse, sexual assault, eating disorders, etc. due to the low frequency and sensitivity of such issues. However, the entry-level professional is expected to appropriately respond to such situations, and SPs can be used to prepare students for such patient interactions in a more realistic fashion. Furthermore, if the student says something inappropriate, does not make proper referral, and/ or follow proper referral procedures, the SP is not harmed while the student learns from the situation.

Our research demonstrates that the athletic training students perceive the encounters with SPs are realistic and worthwhile. Additionally, they feel more comfortable in future encounters with SPs and, most importantly, with actual patients (see related article in this issue of ATEJ).

\section{SP Resources}

To minimize faculty time required to create SP encounters, a template, cases, and associated checklists could be developed by teaching assistants, graduate assistants, or students (individually or in groups). Once the cases and checklists have been created, students can then discuss their accuracy and realism and modify them accordingly. Faculty can make the final revisions before using them with SPs and students. Examples of cases can be found on MedEd Portal, ${ }^{9}$ a site developed in 2005 by the Association of American Medical Colleges that offers a free, peer-reviewed publication service and repository for medical and oral health teaching materials, assessment tools, and faculty development resources. At BSU, athletic training students and theater majors 
have served as SPs as either volunteers or paid through research funding. SPs could also be "funded" by receiving course credit or as part of a class assignment. Our SP encounters have taken place in a small satellite athletic training room, in the athletic training and research lab, and in our Clinical Proficiency Evaluation Room (CPER). For the latter, we converted a small office. ${ }^{4}$ This room is now a physical examination/mini-athletic training room stocked with standard athletic training supplies and a treatment table. In addition, the room has a panoramic view video camera which sends a live feed to a computer in another location, allowing real time evaluation of the student without interference from faculty. For more information regarding the creation of our CPER please refer to the NATA News. ${ }^{10}$

\section{Getting Started}

There are many peer-reviewed publications regarding the use of SPs ${ }^{8,11-14}$ which provide basic information on how SPs are used with medical students and/or provide a description of SP research (eg fidelity, accuracy of SP training, predictive value of performance on an SP encounter, reliability and validity), and can be used to stimulate the use of SPs in athletic training clinical education. Other resources include individuals who oversee an SP program at your institution or in the local area, such as at a hospital, who may be willing to share their facilities, staff, and SPs with your athletic training students. Athletic training students may also find it educational to serve as SPs for students in medical and nursing programs. For programs beginning their own SP programs, we suggest attending the Southern Illinois University School of Medicine Training and Using Standardized Patients for Teaching and Assessment Workshop. ${ }^{15}$ This workshop is considered the "gold standard" to properly prepare educators new to SPs. Furthermore, we recommend that all individuals working with or training SPs should join the Association of Standardized Patient Educators; while the majority of its members are at medical schools, the association welcomes all educators (eg, athletic training, nursing, physical therapy) interested in using SPs.

\section{Conclusion}

While the use of SPs is widespread in medical education and growing in other allied health care fields (eg, nursing, physical therapy), we have seen little use in athletic training. We know through our own experiences that using SPs with athletic training students can enhance learning opportunities. Although many resources (eg, time, facilities, funding) are needed to fully implement such experiences, SPs can still be used on a smaller scale to assist athletic training students' clinical education. We hope more research and use of SPs will be reported in the athletic training literature.

\section{References}

1. Barrows HS, Abrahamson. The programmed patient: A technique for appraising students' performance in clinical neurology. J Med Educ. 1964;39(8):802-805.

2. Ebbert DW, Connors H. Standardized patient experiences: Evaluation of clinical performance and nurse practitioner student satisfaction. Nurs Educ Persp. 2004;25(1):12-15.

3. Yoo MS, Yoo IY. The effectiveness of standardized patients as a teaching method for fundamentals. J Nurs Educ. 2003;42(10):444-448.

4. Black B, Marcoux BC. Feasibility of using standardized patients in a physical therapist education program: A pilot study. J Phys Ther Educ. 2002;16:49-56.

5. Jensen, GM, Richert AE. Reflection on the teaching of ethics in physical therapist education: Integrating cases, theory, and learning. J Phys Ther Educ. 2005;19:78-85.

6. Armstrong, KJ, Weidner, TG, Walker, SE. Athletic training approved clinical instructors' reports of real-time opportunities for evaluating clinical proficiencies. $J$ Athl Train. 2009;44(6):630-638.

7. Walker SE, Weidner TG, Armstrong KA. Evaluation of athletic training students' clinical proficiencies. J Athl Train. 2008;43(4):386-395.

8. Barrows HS. An overview of the uses of standardized patients for teaching and evaluating clinical skills. Academic Med. 1993;68(6):443-445.

9. MedEd Portal. Available at: www.aamc.org/mededportal. Accessed January 24, 2010.

10. Walker SE. Clinical proficiency evaluation room. NATA News. January 2009:32.

11. Adamo G. Simulated and standardized patients in OSCEs: Achievements and challenges 1992-2003. Med Teacher. 2003;25(3):262-270.

12. Wallace P. Following the threads of innovation: The history of standardized patients in medical education. Caduceus. 1997;13(1):13-27.

13. Wallace P. Coaching Standardized Patients for use in the Assessment of Clinical Competence. Springer Publishing Company, LLC; 2007.

14. Williams, R. Have standardized patient examinations stood the test of time and experience? Teach Learn Med. 2004;16(2):215-222.

15. Southern Illinois University School of Medicine. "Training and Using Standardized Patients for Teaching and Assessment Workshop. Available at: http://www.pbli.org/ workshops/index.htm. 